\title{
Patterns of Cancer Occurrence In Nepal
}

\author{
Dhungana $\mathbf{A}^{1^{*}}$, Ghimire $\mathrm{HP}^{2}$ \\ 'Lecturer, ${ }^{2}$ Assistant Professor, Department of Community Medicine, \\ Gandaki Medical College \& Teaching Hospital, Pokhara, Nepal
}

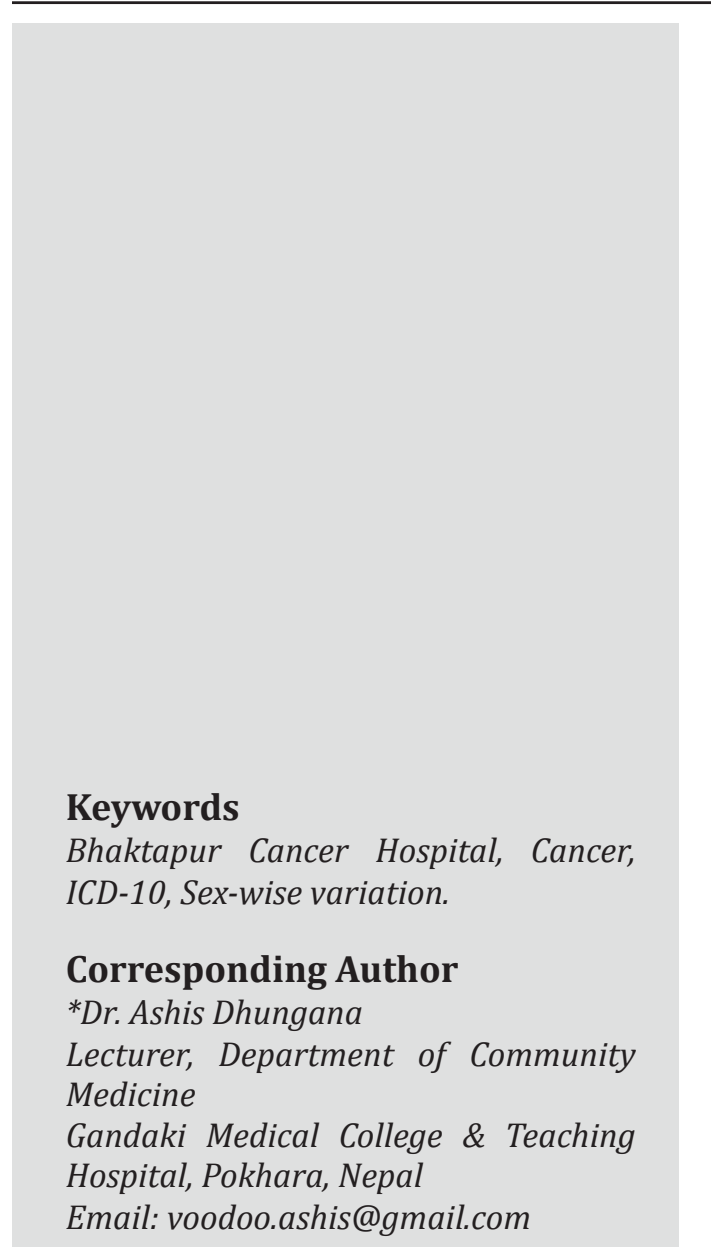

\begin{abstract}
Background: Cancer is a public health problem throughout the world and Nepal is not an exception. Actual information on pattern of cancer morbidity and mortality is possible only from population-based registry, which unfortunately is lacking in Nepal.
\end{abstract}

Objectives: The objective of this study is to determine the pattern of cancer occurrence in Nepal with respect to different pertinent variables.

Methods: A descriptive cross sectional study was done among 198 admitted patients from Bhaktapur Cancer Hospital using semi-structured interview schedule. Data entry and analysis was done on IBM SPSS V20. Descriptive statistical measures were employed.

Results: This study showed that cancer was seen in advanced age group with no sex wise variations. Majority was married, literate, from rural area, of upper caste and upper lower socioeconomic status. Cancer of lung, rectum and bile duct were more frequent in males in contrary to that of breast, ovary and cervix in females. Malignant neoplasm of digestive organs in males and that of female genital organs in females were the commonest to occur according to ICD-10 classification.

Conclusions: Cancer is rapidly emerging non-communicable disease throughout the world. Despite lack of population based disease registry, patterns of disease from this hospital study emphasize prioritizing the health promotive activities against cancer in the general population.

\section{INTRODUCTION}

Cancer is a public health problem throughout the world and Nepal is not an exception. In 2012, there were 14.1 million new cancer cases, 8.2 million cancer deaths and 32.6 million people living with cancer (Within five years of diagnosis) globally. In the same year, an estimated 19 thousands new cancer cases and 14 thousands cancer deaths occurred in Nepal ${ }^{1}$.

Actual information on pattern of cancer morbidity and mortality is possible only from population-based registry, which unfortunately is lacking in Nepal. Hospital based studies have shown that cancers of lung, oral cavity, larynx and stomach in males, and cancers of uterine cervix, breast, lung and ovary in females are the most frequent cancers reported in Nepal. Leukemia is common in case of children. Shifts in the main cancers are noted with different ages, with leukemias and lymphomas in young individuals replaced by lung, oral and stomach cancers in middle aged and lung, stomach and larynx cancers in the older category of males. In females the shift is to breast cancer in young women, then cervical cancer in middle age followed by lung cancer in the very aged. There results can vary between hospitals and regions within the country ${ }^{2}$.

A significant proportion (23\%) of total cancer patients in Nepal seeking cancer care inside the country are found to approach Bhaktapur Cancer hospital ${ }^{2}$. A large body of literature exists on the epidemiology of cancer in the Western world and some Asian countries. But, little has been done in Nepal in this regard. So the present study in the same hospital has been carried out to comprehensively delineate the cancer patterns in context of Nepal taking account of inadequate previous studies. 


\section{METHODS}

A descriptive cross sectional study was done among 198 admitted patients from Bhaktapur Cancer Hospital, a specialized cancer care center, managed by Nepal Cancer Relief Society and located in the Bhaktapur district, Nepal. Study subjects were adult cancer patients, aged 18 and above, admitted in that center during four months of study period and willing to participate in this study. All invasive cancers in categories (C00-C99), precancerous lesions and in-situ carcinomas in categories (D00-D48) from International Classification of Diseases $10^{\text {th }}$ Revision $^{3}$ (ICD-10), diagnosed by histopathology or radiology or other methods, were included in the study. Convenience sampling, a type of non-probability sampling method was used. Those who were seriously ill or in terminal stage or were unable to answer the questions were excluded.

Paper and pencil based interview was done with semi structured interview schedule. Data entry and analysis was done on IBM SPSS V20. Descriptive statistical measures were employed. Written consent was taken from patients, approval from Bhaktapur Cancer Hospital and ethical clearance from Institutional Research Committee. Patients had the right to refuse participation in the study and also the freedom to withdraw from it at anytime. The identity of the respondents and their response were kept confidential and the data were used for research purpose only.

\section{RESULTS}

Out of total 198 patients, 51\% (101) were males and $49 \%$ (97) were females. The sex ratio was 1.04 . Youngest and oldest ages were 19 and 81 years respectively. Age distribution of the cancer patients was left skewed with median age of 54 years and interquartile range $(\mathrm{IQR})=[62$ (third quartile Q3) - 45 (first quartile Q1)] = 17 years.

Since the study was carried out in adult patients above 18 years, 162 (81.8\%) were married, 17 (8.6\%) single and 19 (9.6\%) widowed. Majority of the patients, 136 (69\%), were from rural area and the rest 62 (31\%) were from urban area as per their permanent residence status. Out of total patients, 77 (39\%) were of upper caste. Disadvantaged non-dalit terai caste were $3(1.5 \%)$, dalit $10(5 \%)$, relatively disadvantaged janajatis 50 (25\%), relatively advantaged janajatis $54(27 \%)$ and religious minorities $4(2 \%)$.

Regarding literacy status, $119(60 \%)$ of the patients were literate and the rest 79 (40\%) illiterate. Among the literates, majority had completed secondary education, followed by primary and higher secondary. When their socioeconomic status was assessed, none of them were from the upper socio economic class. Majority 105 (53\%) was from the upper lower class, followed by lower middle class 78 (39\%), lower class $11(5 \%)$ and upper middle class $4(2 \%)$ respectively.

In males, out of total 101 cases, 36 cases were malignant neoplasms of digestive organs (35.6\%). This was followed by malignant neoplasms of respiratory and intrathoracic organs with 17 cases $(16.8 \%)$. Third common cancer with 14 cases $(13.9 \%)$ was of malignant neoplasms of lymphoid, haematopoietic and related tissue (Table 1).

Table 1: ICD classification of cancer and their respective occurrence in males

\begin{tabular}{|c|c|c|c|}
\hline Types of Cancer & ICD Codes & Frequency & Percent \\
\hline $\begin{array}{l}\text { Malignant neoplasms of lip, oral } \\
\text { cavity and pharynx }\end{array}$ & $\mathrm{C} 00-\mathrm{C} 14$ & 7 & $6.9 \%$ \\
\hline Malignant neoplasms of digestive organs & C15-C26 & 36 & $35.6 \%$ \\
\hline $\begin{array}{l}\text { Malignant neoplasms of respira- } \\
\text { tory and intrathoracic organs }\end{array}$ & С30-С39 & 17 & $16.8 \%$ \\
\hline $\begin{array}{l}\text { Malignant neoplasms of bone } \\
\text { and articular cartilage }\end{array}$ & $\mathrm{C} 40-\mathrm{C} 41$ & 10 & $9.9 \%$ \\
\hline $\begin{array}{l}\text { Malignant neoplasms of male } \\
\text { genital organs }\end{array}$ & C43-C44 & 1 & $1 \%$ \\
\hline $\begin{array}{l}\text { Malignant neoplasms of thyroid } \\
\text { and other endocrine glands }\end{array}$ & C73-C75 & 1 & $1 \%$ \\
\hline $\begin{array}{l}\text { Melanoma and other malignant } \\
\text { neoplasms of skin }\end{array}$ & C43-C44 & 1 & $1 \%$ \\
\hline $\begin{array}{l}\text { Malignant neoplasms of meso- } \\
\text { thelial and soft tissue }\end{array}$ & C45-C49 & 7 & $6.9 \%$ \\
\hline Malignant neoplasms of urinary tract & C64-C68 & 6 & $5.9 \%$ \\
\hline $\begin{array}{l}\text { Malignant neoplasms of eye, } \\
\text { brain and other parts of central } \\
\text { nervous system }\end{array}$ & $\mathrm{C} 69-\mathrm{C} 72$ & 1 & $1 \%$ \\
\hline $\begin{array}{l}\text { Malignant neoplasms of } \\
\text { lymphoid, haematopoietic and } \\
\text { related tissue }\end{array}$ & C81-C96 & 14 & $13.9 \%$ \\
\hline Total & & 101 & 100 \\
\hline
\end{tabular}

Fig 1: Age distribution of major cancers in males

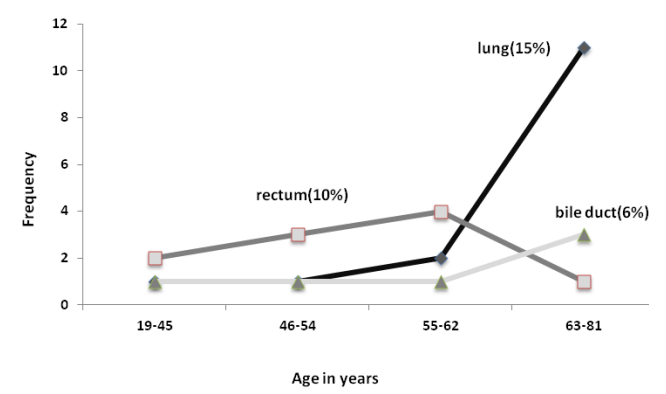


When cancers from individual sites were considered, lung cancer was the most common cancer in males 15 (15\%), followed by cancer of rectum $10(10 \%)$ and cancer of bile duct $6(6 \%)$. Age classification is done according to the quartile values, $\mathrm{Q} 1=45$ years, Median $=54$ years, $\mathrm{Q} 3=62$ years. The lowest and highest age of cancer patients in this study are 19 and 81 years respectively (Fig 1).

In case of females, malignant neoplasm of female genital organs were the most frequent type of cancers followed by malignant neoplasm of digestive organs and malignant neoplasm of breast (Table 1). Among individual cancers, breast cancer was the most common cancer in females 22 (23\%), followed by cancer of ovary 13 (13\%) and cancer of cervix 12 (12\%) (Fig 2).

Table 2: ICD classification of cancer and their respective occurrence in females

\begin{tabular}{llll}
\hline $\begin{array}{l}\text { Types of Cancer } \\
\begin{array}{l}\text { Malignant neoplasm of lip, oral } \\
\text { cavity and pharynx }\end{array}\end{array}$ & C00-C14 & 3 & $3.1 \%$ \\
$\begin{array}{l}\text { Malignant neoplasm of diges- } \\
\text { tive organs }\end{array}$ & C15-C26 & 23 & $23.7 \%$ \\
$\begin{array}{l}\text { Malignant neoplasm of respira- } \\
\text { tory and intra-thoracic organs }\end{array}$ & C30-C39 & 7 & $7.2 \%$ \\
$\begin{array}{l}\text { Malignant neoplasm of meso- } \\
\text { thelial and soft tissue }\end{array}$ & C45-C49 & 1 & $1 \%$ \\
$\begin{array}{l}\text { Malignant neoplasm of breast } \\
\begin{array}{l}\text { Malignant neoplasm of female } \\
\text { genital organs }\end{array}\end{array}$ & C50 $51-C 58$ & 30 & $30.9 \%$ \\
$\begin{array}{l}\text { Malignant neoplasm of urinary tract } \\
\begin{array}{l}\text { Malignant neoplasm of eye, } \\
\text { brain and other parts of central } \\
\text { nervous system }\end{array}\end{array}$ & C69-C72 & 22 & $22.7 \%$ \\
$\begin{array}{l}\text { Malignant neoplasm of } \\
\text { lymphoid, hematopoietic and } \\
\text { related tissue }\end{array}$ & C81-C96 & 7 & $2.1 \%$ \\
\hline \begin{tabular}{l} 
Total \\
\hline
\end{tabular} & & 97 & $7.2 \%$ \\
\hline
\end{tabular}

Fig 2: Age distribution of major cancers in females

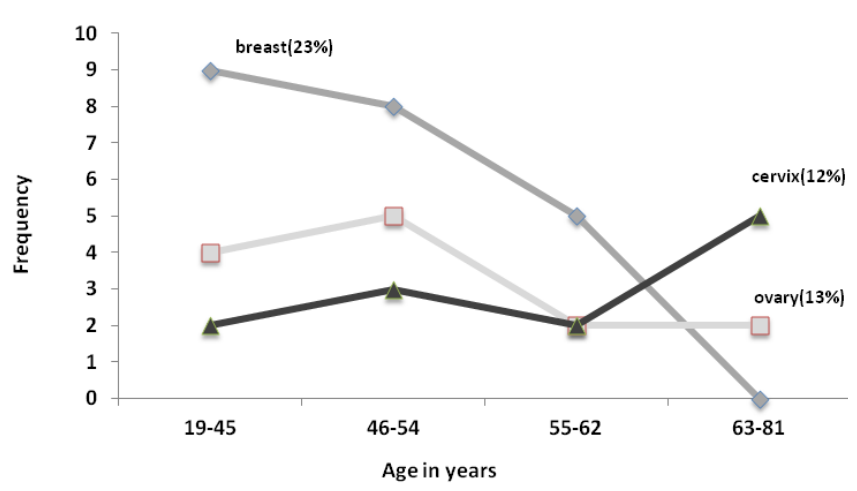

Fig 3: Top 10 cancers in both sexes

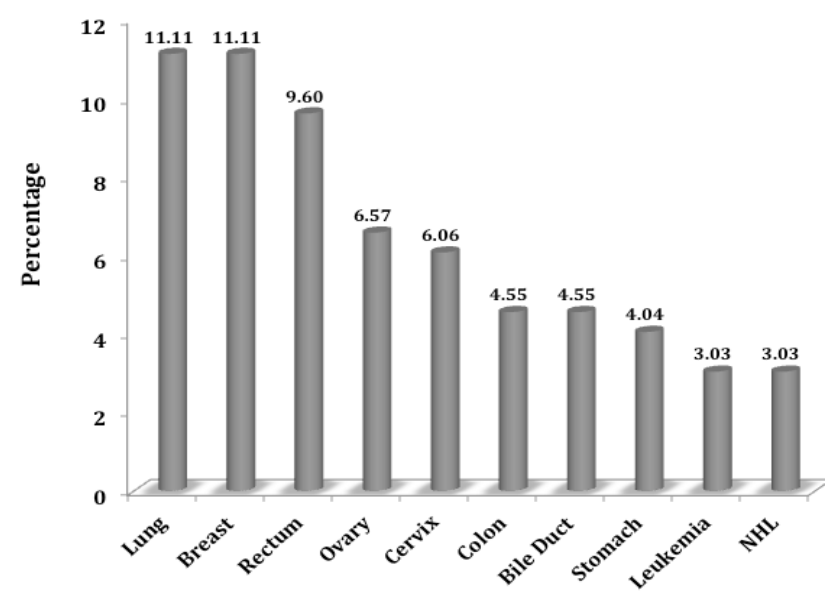

When 198 cancer patients of both sexes were considered, cancers of lung, breast, rectum, ovary and cervix were the most frequent cancers respectively (Fig 3).

\section{DISCUSSION}

Demographic characteristics of the study subjects include sex ratio of 1.04, age range of 62 years (81 - 19) and median age of 55 years. So cancer was more commonly seen in advanced age group though the types of cancer varied with age and sex. Binu VS et al in a study from Manipal College of Medical sciences, Nepal reported that out of total 957 cancer cases, $51.8 \%$ were males and $48.2 \%$ females with male to female ratio $1.1: 1$. The median age of males and females were 63 and 60 years respectively ${ }^{4}$. On contrary, El Helal TA et al reported in a study from Jordan that male to female ratio was $1.5: 1$; the median age for males was 43 years and for females it was 45 years ${ }^{5}$.

According to ICD classification, this study found 36 (35.6\%) cases were malignant neoplasm of digestive organs, followed by malignant neoplasm of respiratory and intra-thoracic organs with 17 cases (16.8\%) among males. Third common cancer with 14 cases $(13.9 \%)$ was of malignant neoplasm of lymphoid, hematopoietic and related tissue. In case of female, malignant neoplasm of female genital organs (30.9\%) were the most frequent type of cancers followed by malignant neoplasm of digestive organs $(23.7 \%)$ and malignant neoplasm of breast $(22.7 \%)$.

A study from Western Nepal found that among males, $33.1 \%$ of all cancers were in the respiratory system, 
followed by digestive organ cancers (23.2\%). Among females, $28.4 \%$ cancers were related to the reproductive system, $22.8 \%$ to the respiratory system and $14.1 \%$ to digestive organs ${ }^{4}$. This study found that cancer of lung, rectum and bile duct were more frequent in males in contrary to that of breast, ovary and cervix in females. In males, cancers of lung and bile duct were seen less in younger and middle age group but more in older age group. In case of rectal cancer, patients from younger and middle age were more affected while it was seen less in older patients. Breast cancer was found more in younger age group and less in older patients. Cervical cancer was just the opposite with older people more affected. Number of ovarian cancer increased from younger age to adult and again decreased in older age group. Pradhananga KK et al found that the most common site in males was the lung, followed by the oral cavity and stomach; while the first three in females were cervix uteri, breast and lung. Shifts in the main cancers were noted with different ages, with leukemias and lymphomas in young individuals replaced by lung, oral and stomach in middle age and lung, stomach and larynx in the oldest category of males. In females the shift was to breast in young women, then cervix in middle age followed by lung in the very aged. There was also variation between hospitals, but this appeared largely due to the differences in the therapeutic modalities available in different institutions ${ }^{2}$. In similar studies, lung cancer in males and breast cancer in females are the most common cancers ${ }^{6,7,8}$.

\section{CONCLUSION}

Cancer is a global disease. It is an important emerging noncommunicable disease in developed as well as developing countries. This study showed cancer is equally common in both sexes, more in advanced age group and people from lower and middle socio-economic classes are more affected. Cancer of lung, rectum and bile duct in males, while cancers of breast, ovary and cervix in females are the more frequent types; further varying with different age. This emphasizes prioritizing the health promotive activities against cancer in the general population.

\section{REFERENCES}

1. Torre LA, Bray F, Siegel RL, Ferlay J, Lortet-Tieulent J, Jemal A. Global cancer statistics, 2012. CA: A Cancer Journal for Clinicians. 2015 Mar 1; 65(2): 87-108.

2. Pradhananga KK, Baral M, Shrestha BM. Multiinstitution hospital-based cancer incidence data for Nepal: An initial report. Asian Pac J Cancer Prev. 2009;10(2): 259-62.

3. World Health Organization. ICD-10: International statistical classification of diseases and related health problems: tenth revision. World Health Organization. 2004.

4. Binu V, Chandrashekhar T, Subba S, Jacob S, Kakria A, Gangadharan P, et al. Cancer pattern in Western Nepal: a hospital based retrospective study. Asian Pacific Journal of Cancer Prevention. 2007; 8(2): 183-86.

5. El Helal TA, Bener A, Galadari I. Pattern of cancer in the United Arab Emirates referred to AL-Ain hospital. Annals of Saudi Medicine. 1997; 17: 506-09.

6. Khan G, Thapa R, Adhikari D, Rajbhandari M, Dwa P, Shrestha $\mathrm{S}$, et al. Cancer prevalence trend in Central region of Nepal. Journal of Chitwan Medical College. 2013; 3(3): 22-25.

7. Subedi KS, Sharma P. Cancer Treatment in Nepal: A historical background, development of treatment facilities, epidemiology and challenges for prevention and control of cancer. Austral - Asian Journal of Cancer. July 2012; 11(3): 205-12.

8. Moore MA, Ariyaratne Y, Badar F, Bhurgri Y, Datta K, Mathew A, et al. Cancer epidemiology in South Asia past, present and future. Asian Pac J Cancer Prev. 2010; 11(Suppl 2): 49-66.

\section{Conflict of Interest}

None 